\title{
Aspectos da gestão que influenciam o processo de planejamento municipal e regional do Sistema Único de Saúde
}

\author{
Aspects of management that influence the process of municipal and regional \\ planning of the Unified Health System
}

Fernanda Bergamini Vicentine ${ }^{1}$, Thatiane Delatorre ${ }^{2}$, Aline Fiori dos Santos Feltrin ${ }^{1}$, Liliane Cristina Nakata ${ }^{1}$, Letícia Soares $^{1}$, Janise Braga Barros Ferreira ${ }^{3}$

\begin{abstract}
RESUMO:
Modelo do estudo: Estudo descritivo, transversal, com abordagem qualitativa. Objetivos do estudo: descrever e analisar a opinião de gestores e técnicos do setor saúde sobre os instrumentos e os recursos que integram o processo de planejamento no Sistema Único de Saúde. Metodologia: foram entrevistados 26 participantes, entre gestores e técnicos dos municípios e do estado que compõem o Departamento Regional Saúde XIII. Para análise dos dados, utilizou-se a Análise de Conteúdo em sua vertente temática. Resultados: o espaço de planejamento e cogestão regional, conhecido como Colegiado de Gestão Regional, se mostrou potente para a troca de experiências, mas apresentou fragilidades em relação a falta de coesão pelos diferentes níveis de conhecimento dos gestores e condições financeiras diversas entre os municípios. Notouse que a permanência dos gestores nos cargos foi positiva, desde que acompanhada por práticas de educação permanente. Por fim, a construção e a execução do planejamento tiveram como grandes barreiras o subfinanciamento e a judicialização na saúde, levando alguns municípios a escolha de políticas indutoras do nível federal e a terceirização da contratação de recursos humanos. Conclusão: O Colegiado de Gestores Regional apresentou grande potencial e poderia colaborar com a diminuição de retrocessos, a cada descontinuidade política, no processo de planejamento municipal e regional se fosse dado maior enfoque à coordenação federativa e ao aporte técnico do estado.
\end{abstract}

Palavras-chave: Planejamento em saúde, Regionalização, Descentralização; Gestão em saúde; Sistema único de saúde.

1. Doutoranda pelo Departamento de Medicina Social da Faculdade de Medicina de Ribeirão Preto FMRPUSP.

2. Mestranda pelo Departamento de Medicina Social da FMRP-USP.

3. Professora Doutora do Departamento de Medicina Social da FMRP-USP.

Os autores declaram que não houve conflito de interesses na concepção deste trabalho.
CORRESPONDEENCIA: Fernanda Bergamini Vicentine Departamento de Medicina Social Hospital das Clínicas da FMRP-USP Campus Universitário $\mathrm{s} / \mathrm{n}$ - Monte Alegre 14048-900 - Ribeirão Preto / SP

Recebido em 29/11/2017 Aprovado em 22/05/2018 


\begin{abstract}
:
Study model: Descriptive, cross-sectional study with a qualitative approach. Objectives of the study: to describe and analyze the opinion of managers and technicians of the health sector on the instruments and resources that integrate the planning process in Unified Health System. Methodology: 26 participants were interviewed, among managers and technicians from the municipalities and the state that make up the Regional Health Department XIII. To analyze the data, we used Content Analysis in its thematic aspect. Results: The regional planning and co-management space, known as the Regional Management Collegiate, proven to be influential for the exchange of experiences, but it showed weaknesses about the lack of cohesion due to the different levels of managerial knowledge and diverse financial conditions among the municipalities. It was noticed that the permanence of the managers in the positions was positive, as long as accompanied by practices of permanent education. Finally, the construction and execution of the planning had as main barriers the underfinancing and the judicialization in health, leading some municipalities to choose policies to induce the federal level and outsourcing the hiring of human resources. Conclusion: The Collegiate of Regional Managers presented great potential and could collaborate with the reduction of setbacks, with each political discontinuity, in the process of municipal and regional planning if the greater focus given to federative coordination and state technical contribution.
\end{abstract}

Keyword: Health Planning; Regional Health Planning; Decentralization; Health Management; Unified Health System.

\section{INTRODUÇÃO}

No Brasil, uma proposta relativamente recente, trazida pelo Pacto pela Gestão ${ }^{1}$ foi o Sistema de Planejamento do Sistema Único de Saúde (PlanejaSUS), que estabeleceu pontos prioritários para a pactuação do planejamento. ${ }^{1}$ Considerando o seu elenco de instrumentos básicos - Plano de Saúde (PS), Programação Anual de Saúde (PAS) e Relatório Anual de Gestão (RAG), ${ }^{2}$ o PlanejaSUS pode ser compreendido como um catalizador do processo de planejamento do SUS. Em síntese, os seus instrumentos têm por finalidade apoiar o gestor na condução do SUS de modo a alcançar a eficiência e a efetividade das ações, o aperfeiçoamento da avaliação dos serviços prestados, além de possibilitar a continuidade do processo de planejamento com transparência e o exercício da gestão participativa. O Pacto de Gestão também instituiu os Colegiados de Gestão Regional (CGR) como instâncias permanentes de pactuação, cogestão e de decisão dentro das Regiões de Saúde (RS), integrando-os com as Comissões Intergestores Bipartite ( $\mathrm{ClB}$ ) e as Comissões Intergestores Tripartite (CIT). ${ }^{3}$ Destaca-se ainda que o Decreto no 7.508/2011, ${ }^{4}$ trouxe alterações ao planejamento regional, entre elas, a re- tomada da nomenclatura CIR (Comissão Intergestores Regional) para nomear os espaços de cogestão regional, equivalente aos CGR trazidos pelo Pacto pela Saúde. ${ }^{1}$

Deste modo, essa organização regionalizada, fundamento para o processo de planejamento e advinda da descentralização da gestão, tem sido identificada como diretriz estruturante para a garantia do direito à saúde de maneira resolutiva e equitativa. ${ }^{5}$

No entanto, mesmo com os avanços em relação à sistematização das ferramentas de planejamento e aos espaços de cogestão como cenários operativos do planejamento, a dependência de instâncias superiores, como a CIB, permaneceu para que as decisões das CIR sejam aprovadas e implementadas. ${ }^{6}$

Sendo assim, esse estudo teve como objetivo geral descrever e analisar a opinião de gestores e técnicos do setor saúde sobre o processo regional de planejamento do SUS e seus instrumentos e recursos.

\section{MATERIAL E MÉTODOS}

O estudo foi desenvolvido no território do Departamento Regional de Saúde (DRS) XIII, ór- 
gão da Secretaria de Estado da Saúde de São Paulo (SES SP), composto por 26 municípios, com uma população estimada de 1.327.989 habitantes. ${ }^{7}$ Este DRS é conformado por três Regiões de Saúde (Aquífero Guarani, Horizonte Verde e Vale das Cachoeiras) e seus respectivos CGR ou CIR, tendo o município de Ribeirão Preto como sede administrativa e polo assistencial regional.

Para o estudo, os municípios das três Regiões de Saúde (RS) foram agrupados, segundo as Faixas de classificação do PlanejaSUS, a partir do seguinte critério de inclusão: Grupo A: municípios com menos de 10.000 habitantes, correspondente à Faixa 1; Grupo B: municípios entre 10.000 e 50.000 habitantes, correspondente à Faixa 2; e Grupo C: municípios com mais de 50.000 habitantes, que correspondem às Faixas 3, 4 e $5^{2}$. Foi selecionado um município de cada grupo (A, B e C) por RS. Na RS onde existia mais de um município classificado no mesmo grupo, a escoIha foi realizada por meio de sorteio. Assim, obtiveram-se três municípios por RS, totalizando nove.

A coleta de dados ocorreu em fonte primária produzida junto aos atores dos municípios selecionados. Partindo do recorte empírico, foram entrevistados dois técnicos do setor de planejamento e o gestor de cada um dos nove municípios e dois técnicos e o gestor do DRS XIII, totalizando 26 sujeitos. Quatro possíveis participan- tes não retornaram as ligações ou desistiram de participar da pesquisa.

Foi utilizada a entrevista semiestruturada para a coleta dos dados, tendo como eixo temático principal o Processo de Planejamento no SUS. $O$ instrumento foi organizado em quatro blocos de perguntas, sendo eles: o processo de planejamento no município e no CGR; a gestão da informação; os instrumentos de planejamento; e o sistema de planejamento do SUS (Planejasus). As entrevistas foram audiogravadas, transcritas, e foi realizada a Análise de Conteúdo em sua vertente temática. ${ }^{8,9}$

O estudo contemplou as recomendações da Comissão Nacional de Ética em Pesquisa CONEP e foi aprovado pelo Comitê de Ética em Pesquisa do Centro de Saúde Escola da Faculdade de Medicina de Ribeirão Preto-USP (protocolo no 342/CEP/CSE-FMRP-USP).

\section{RESULTADOS E DISCUSSÃO}

O Tema "Espaços e recursos da gestão que influenciam o processo de construção dos instrumentos de planejamento do SUS" foi composto por três núcleos de sentido (Figura 1) construídos a partir da Análise de Conteúdo ${ }^{8,9}$ dos dados obtidos em diálogo com o referencial teórico do PlanejaSUS, ${ }^{1}$ que serão apresentados a seguir.

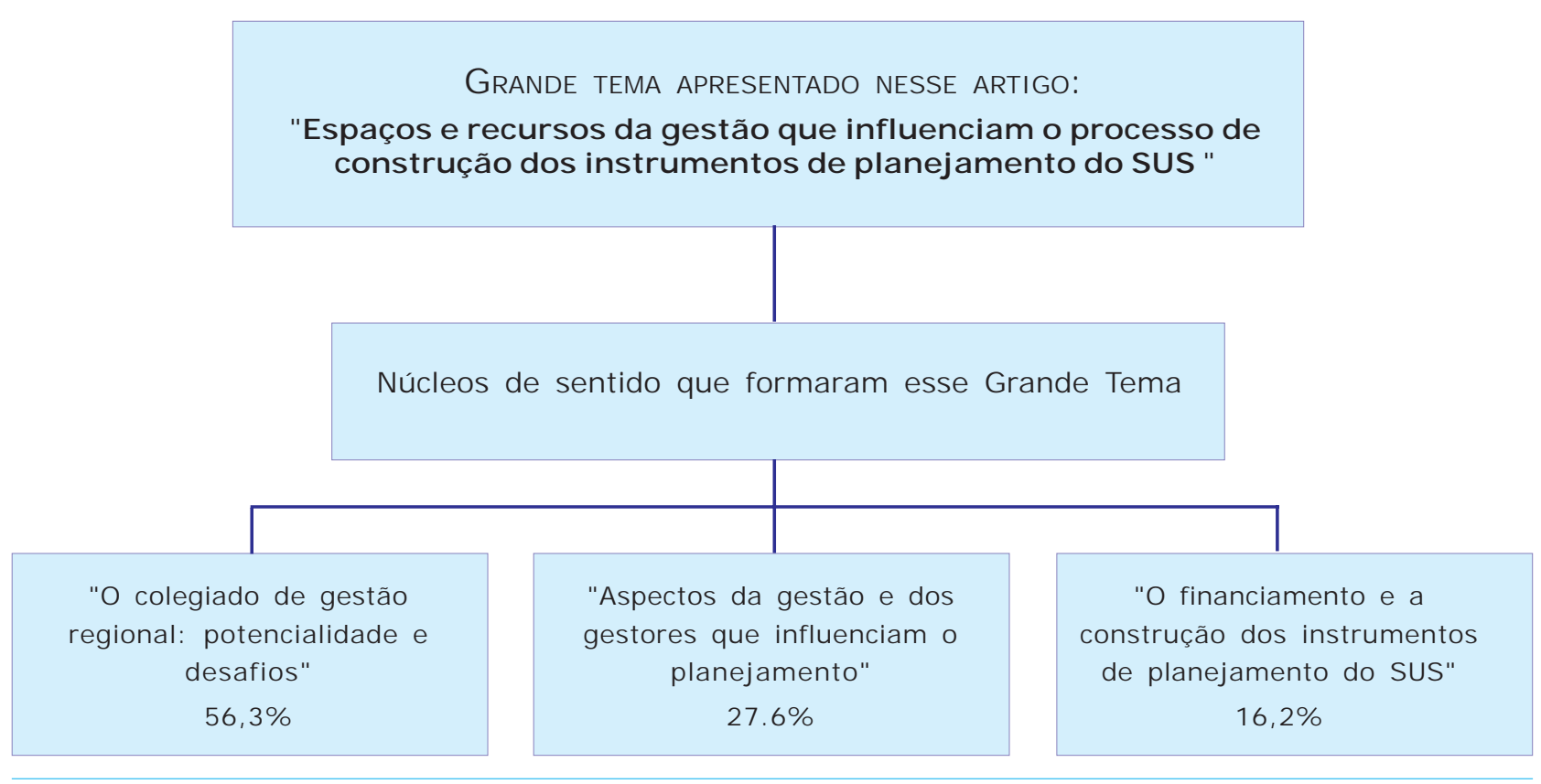

Figura 1: Núcleos de sentido que compuseram o Grande Tema "Impacto da gestão no processo de planejamento". 
No núcleo "O colegiado de gestão regional: potencialidade e desafios" emergiram questões referentes ao funcionamento dos CGR. Os técni$\cos$ e gestores municipais pontuaram algumas potencialidades e limitações relacionadas ao funcionamento desse espaço de cogestão. Entre as potencialidades, foi frequentemente apontada a permanente troca de experiências e informações e o recebimento de orientações, que auxiliam no processo de planejamento dos municípios.

\begin{abstract}
"Como fórum de discussão e de troca de experiências é permanente, ele traz para nós uma série de esclarecimentos, de outras visões que nos permitem aprimorar as nossas ações em relação ao planejamento." (E6)
\end{abstract}

Além dessa troca, o papel de condução do DRS apareceu nas falas como um aspecto essencial para a construção dos instrumentos de planejamento. Esse achado corrobora o papel de coordenação do Estado, que tem o potencial de viabilizar a sustentabilidade do processo de regionalização, independentemente da renovação do quadro de gestores municipais. ${ }^{10}$

Os instrumentos normativos pro planejamento são ainda muito recentes, [...] nós estamos de certa maneira aprendendo a construir isso. É claro que neste momento a DRS acaba assumindo mesmo o papel de... mais evidência, cabe a ela articular os municípios, tomar as iniciativas. (E6)

Esse espaço ainda foi entendido pelos representantes do DRS como potente colaborador para avançar no sentido da regionalização da saúde, ao relatar que os membros dos CGR assumiram a postura de que a RS deve ser autossuficiente e o mais resolutiva possível.

Porque eles [municípios] já desenvolveram aquela mentalidade de que cada região tem que ser o mais autossuficiente possível (...) o colegiado ajudou muito... no sentido de esses pacientes estarem retornando para sua região de saúde, para que ela seja o mais resolutiva possível. (E26)
Por outro lado, nas falas que apontaram as limitações do CGR foi relatada a dificuldade em compreender a dinâmica do CGR por parte de gestores e técnicos que assumiram seus cargos pouco tempo antes da entrevista, que muitas vezes não têm experiência na gestão. Essa incompreensão por parte de alguns leva a questionamentos em relação a esse espaço de cogestão enquanto sua potencialidade para se realizar o planejamento regional. Essa dificuldade de compreender a dinâmica do CGR, em contrapartida ao achado anterior, pode apontar para falhas na coordenação desse colegiado, reduzindo a potencialidade desse espaço para a realização do planejamento.

A gente não chega a entrar nos detalhes de planejar alguma coisa [no CGR], na verdade a gente só discute o momento, as coisas que estão acontecendo no dia, dos problemas que vem enfrentando os municípios. (E12)

Outro aspecto, que influenciou negativamente a compreensão sobre a dinâmica desse espaço, foi a disponibilidade dos gestores e técnicos dos municípios para participar das reuniões. Essa dificuldade foi mais frequente para os municípios de pequeno porte, pois eles não têm uma equipe de planejamento, sendo na maioria das vezes todo o trabalho centrado em um único indivíduo, o que inviabiliza a presença em todas as reuniões. Esse achado encontra ressonância na pesquisa realizada pelo $\mathrm{MS}^{2}$ que apontou que o responsável pela informação para o planejamento em nível local, em municípios de pequeno porte na Região Sudeste, é o gestor local.

Colegiado... pelas pouquíssimas vezes que eu fui, eu entendo que as vezes eles não concordam com certas coisas que os municípios colocam... que as vezes eu não sei... não sei explicar certinho o porque... (...) mas depois tudo vai se adequando, vai se acertando, eles vão ajudando, vão se informando... (E9)

Outra dificuldade relatada pelos entrevistados foi a fragmentação do CGR motivada por diferentes níveis de conhecimento entre os membros e por desigualdades financeiras entre os 
municípios. Estudos corroboram a segunda parte do relato de que grandes desigualdades financeiras podem levar a conflitos no espaço de cogestão do CGR, uma vez que quando o processo de descentralização não vem acompanhado da coordenação federativa e da cooperação solidária pode aumentar as desigualdades regionais, a fragmentação dos serviços e a competitividade. ${ }^{11} \mathrm{~A}$ falta de coordenação federativa também apareceu no relato sobre a carência de uma definição do papel de cada município dentro da RS, o que leva a conflitos na gestão municipal e a problemas de recursos financeiros para custear os serviços de saúde. Tendo em vista a grande heterogeneidade dos municípios, mesmo entre aqueles que compõem um determinado CGR, espera-se que haja certa flexibilidade na distribuição de responsabilidade e conformações de diferentes acordos entre os gestores envolvidos. ${ }^{11}$

Eu acho que nosso colegiado ele é bem segmentado (...) quando a gente tenta chamar para uma reunião os 9 municípios a gente sente uma dificuldade muito grande, até porque a gente tem dois municípios financeiramente um pouco mais abastados e sete municípios muito diferentes, de realidades muito diferentes, eu acho que isso contribui negativamente para o CGR (...). (E20)

(...) é definir qual é o papel que (o município) quer ter no cenário regional e nacional... regional, estadual e nacional, a partir dessa definição aí é que se vai fazer uma gestão (...) enquanto o município não se definir a gente vai ficar refém aí de uma política totalmente individualizada enquanto município (...) eu sinto uma dificuldade de cobrar o que eu não ofereço. (E20)

Essa dificuldade em definir o papel de cada município dentro da RS também trouxe consequências para a pactuação dos instrumentos de planejamento, como a Programação Pactuada e Integrada (PPI), sendo relatada dificuldade para ordenar a demanda e definir o repasse de orçamento na região. A PPI é um instrumento formal de pactuação de recursos e não deveria ser usa- da como um instrumento de gestão independente do plano de saúde ou se sobrepor a ele. ${ }^{2}$ Pressupunha-se a coordenação da PPI pela gestão estadual. ${ }^{2}$

(...) programação pactuada integral, que é a PPI, que aqui no Estado de São Paulo não funcionou. (...) qual é o papel de cada município, o que é que eu vou mandar, ter essa coisa ordenada, escalonada e com um aporte financeiro também. (E8)

Além das dificuldades relatadas pelos técnicos e gestores municipais, os representantes do DRS verbalizaram que sentiam dificuldades para entender os problemas vivenciados pelos municípios, pois estão distantes de suas realidades. Levando-se em consideração o papel que o estado deve desempenhar, segundo o PlanejaSUS, ${ }^{2}$ a sua responsabilidade é de assessorar e coordenar o processo de planejamento, tanto local quanto regional, com adaptação às diferentes realidades locais. Porém, se existe dificuldade para que essas realidades sejam compreendidas e se não há relatos para que essa limitação seja transposta, dificilmente o planejamento será realizado de maneira satisfatória. Esse achado corrobora aspectos sobre o perfil do apoiador destacado por Campos, ${ }^{12}$ o qual afirma que um apoiador ou assessor precisa deter um conhecimento mínimo na área para poder contribuir de forma a clarear as dificuldades dos espaços onde atuam.

Eles trazem problemas que às vezes a
gente tá aqui, você não está localmente,
você não consegue visualizar, porque uma
coisa é você olhar um dado, outra coisa
é você estar vivenciando esse dado lá na
ponta; então eles têm trazido muitos pro-
blemas, muitas dificuldade e às vezes até
soluções que um município consegue
aproveitar. (E24)
O núcleo “Aspectos da gestão e dos gestores que influenciam o planejamento" diz respeito às características da gestão e dos recursos humanos (gestores) que impactam de alguma maneira, positiva ou negativa, o planejamento em saúde. Com relação aos aspectos da gestão que se mostraram positivos, destacou-se a continui- 
dade das pessoas que compõem a equipe de planejamento, mantidas independentemente da troca de secretário ou do prefeito. Há relatos de que esse tipo de escolha traz avanços ao processo de planejamento, pois o conhecimento da equipe tende a se aprimorar com o passar dos anos e a experiência adquirida nessa área é um fator que gera impactos positivos ao processo.

Nós avançamos muito nessa ultima gestão (...) pela equipe continuar junto, favorecendo este progresso dentro da secretaria. (...) nossa equipe tem sido mantida, independente da troca de prefeito e secretário. (E23)

No município a facilidade é que tem pessoas que há muitos anos estão na saúde e que foram adquirindo experiência através dos anos e que são pessoas muito importantes e que acabam trazendo um diferencial. (E13)

Por sua vez, a alteração da equipe a cada troca de gestão traz descontinuidade e a necessidade de despender tempo para que os novos técnicos tomem conhecimento sobre suas funções e os instrumentos de planejamento. Esse processo, denominado descontinuidade administrativa, adquire um tom problemático quando está relacionado à descontinuidade de atividades e programas independentemente de sua efetividade anterior. Esse cenário pode ser mais drástico quando há um número grande de cargos de confiança em direções, chefias, assessorias sendo substituídos de maneira abrupta, somando-se isso à falta de clareza sobre as estratégias a ser desenvolvidas pelos novos ocupantes desses cargos e a perda das memórias institucionais pelo próprio rodízio de cargos, resultando em uma cisão em boa parte das atividades operacionais ${ }^{13}$. Apesar disso, em um estudo realizado em 2001, sobre continuidade e descontinuidade administrativa, os autores depararam com respostas que indicaram que $88 \%$ dos programas tinham continuidade, independente da mudança de figuras políticas após as eleições ${ }^{13}$. Pode-se questionar a partir desses achados a existência de uma sensação de descontinuidade devido ao impacto que a troca de gestores e técnicos traz ao CGR, devi-

do à diferentes níveis de conhecimento prévio que esses trabalhadores têm ao assumir cargos na gestão. Todavia, não necessariamente isso resulte à longo prazo em um impacto significativo na continuidade das políticas públicas, sendo que o direcionamento do estado, enquanto DRS, e os instrumentos de planejamento deveriam servir como meio para garantir uma continuidade administrativa, independentemente da descontinuidade política nos municípios ${ }^{3}$.

(...) porque assim a rotatividade do qua-
dro de funcionários é muito grande, e eles
acabam não tendo muitas vezes uma
pessoa experiente que possa ajudar o
secretário e ser um facilitador. (E13)

Com a mudança da gestão tudo tem que ser reexplicado e recomeçado, isso acontece toda vez que muda o gestor. (E16)

Em contrapartida, foi percebida a necessidade de haver cursos de atualização para aqueles que se mantêm na gestão por longos períodos. Esse achado corrobora um dos objetivos do PlanejaSUS que é promover a educação permanente em planejamento para os profissionais que atuam nessa área. Somam-se a isso as falas anteriores sobre o desconhecimento do processo de planejamento ao assumir cargos técnicos e de gestão, reforçando a necessidade de cursos contínuos na área de planejamento em saúde.

Tipo esse nosso relatório de gestão novo e a... (...) como é que fala? Plano. Eu não sabia fazer, nunca soube, e olha que eu já fui... oito anos que eu fui secretária, não, nunca soube fazer. (E21)

Esses aspectos não são exclusivos do Brasil, tendo em vista que a Organização Mundial de Saúde (OMS) ${ }^{14}$ aponta estratégias para a área de recursos humanos (RH) à curto, médio e longo prazo. À curto prazo com ênfase ao treinamento em serviço e desenvolvimento de políticas para a fixação de RH. À médio prazo recomenda-se a realização de estudos da implementação e do impacto das políticas de formação e treinamento, bem como o desenvolvimento de sistemas de informação de RH. E, à longo prazo, aponta para o fortalecimento da capacidade de formuladores de 
política e construção de infraestrutura. O PlanejaSUS ${ }^{2}$ traz aspectos relativamente semeIhantes para curto e médio prazo, mas sem o enfoque na fixação de profissionais, apesar de reconhecer que a rotatividade de $\mathrm{RH}$ em áreas da gestão pode causar impactos negativos e comprometer o processo de continuidade do planejamento. Ibañez ${ }^{15}$ reforça a necessidade de se criar uma política mais clara de fortalecimento de quadros institucionais, com perfil público e estável para a gestão do SUS.

O sistema do PlanejaSuS também incentiva em seu escopo a inserção da cultura de planejamento. Esse objetivo do sistema encontra correspondência na fala dos entrevistados, quando trazem que um dos empecilhos para fazer o planejamento é o próprio processo de trabalho da equipe. Muitos participantes referiram falta de tempo devido à alta demanda de problemas que têm que resolver no dia a dia. Se por um lado o planejamento é deixado de lado devido à grande quantidade de problemas inesperados do dia a dia, por outro existe a necessidade de reconhecer as limitações do planejamento como ferramenta capaz de controlar o futuro ${ }^{16}$. Assim, os gestores e técnicos deveriam estar preparados para ambas as tarefas, de planejar ações futuras e definir aonde se quer chegar e quais as ações necessárias para isso, tendo a compreensão de que dentro do planejamento não será possível prever todos os acontecimentos futuros ${ }^{17}$. Devese enfatizar também que o "não planejar" leva à execução das atividades segundo a visão de mundo de cada ator social envolvido no Sistema de Saúde (SS), resultando em uma Rede de atenção à Saúde (RAS) fragmentada, desarticulada e em desacordo com os princípios do SUS ${ }^{18}$.

Agora o nosso município, assim a gente trabalha e... não tem muito planejamento, eu acho que falta isso, as coisas acontecem para depois você resolver (...) não deveria ser dessa forma, mas infelizmente é assim que acontece, então os recursos eles são finitos e as coisas acontecem primeiro e aí depois você planeja, aí não dá tempo, por aí você já não tem mais, falta dinheiro, falta recurso. (E19)
Outros aspectos da organização da gestão que levam a dificuldades na realização do planejamento, exemplificada nas falas abaixo, podem estar relacionados a centralização do processo de planejamento em uma pessoa ou apenas na equipe de planejamento e a fragmentação do processo de trabalho, com falhas na comunicação inter-departamental e desconhecimento mútuo das ações realizadas. A pesquisa feita pelo MS, que embasou o PlanejaSUS, também apontou a existência de fragmentação no processo de planejamento, com ênfase na área de orçamento, sem haver relação entre esse achado e o tamanho do município ${ }^{2}$. Testa ${ }^{19}$ faz essa análise segundo a relação de poder, enfatizando a importância de um processo participativo para a elaboração das propostas programático-estratégicas do planejamento, possibilitando a distribuição de poder e a mudança das relações por meio da formação de uma consciência sanitária social. Dessa maneira, obtém-se maior coerência no processo de planejamento e de sua execução.

Esse plano era feito assim por uma pessoa que trabalhava direto com o secretário, ela fazia isso, e fazia sozinha, e depois ninguém via. (E19)

Essa parte de agendamento, de circulação da rede, de toda a rede... essa parte aí é com ela... já não tenho acesso, meu departamento mesmo é departamento de compra, auditoria, mas aqui ligada à secretaria, dentro da secretaria. (E19)

Nesse sentido, as características dos atores sociais que trabalham com o planejamento no município influenciam de maneira significativa a sua condução. Segundo o PlanejaSUS², inserir a cultura do planejamento na rotina da gestão é um avanço, mas também um desafio, pois envolve tanto a postura individual e técnica, quanto a mobilização e engajamento neste exercício. Sendo que as características positivas mais ressaltadas pelos entrevistados foram a disponibilidade para se envolver no processo e a boa vontade de quem faz o planejamento. Esta última, no sentido de buscar soluções inovadoras e abrir-se a novos conhecimentos e à colaboração de outras 
pessoas para a realização do planejamento mais adequado, tanto com relação ao aporte financeiro, quanto com as necessidades da população.

Eu busco muitas coisas, blocos de financiamento “ah, eu não posso pagar recursos humanos, não sei o que..." mas eu descobri que no Qualis Mais eu tenho já pactuado $30 \%$ pra consumo e $70 \%$ pra funcionário, então eu falo "não, eu tenho como pagar sim... eu tinha já no bloco de financiamento". (E10)

[sobre o planejamento participativo] Agendamos com as unidades, todo mundo teve essa participação, foi a primeira vez que isso aconteceu (...) foi muito bom, a gente aprendeu muito. (E19)

Outro ponto que pode ser salientado é a dificuldade de institucionalização do planejamento nas esferas de governo ${ }^{2}$. Essa dificuldade é histórica, tendo em vista o próprio processo de implementação do SUS, em meio ao contexto neoliberal mundial que reforçava a retirada do Estado no fornecimento de serviços de saúde. No Brasil, a gestão do SS é tida como elemento central para a sua implantação e operacionalização, sendo a gestão municipal a grande protagonista na execução das políticas de saúde após a descentralização do SUS ${ }^{20}$. Por se tratar de um processo à curto, médio e longo prazo, o planejamento não deveria ter tamanha dependência de características pessoais ou estar centrado apenas em um setor da Secretaria de Saúde. Deveria ser transversal a todos os setores da SMS e construído de maneira compartilhada. ${ }^{17}$

No núcleo intitulado 'O financiamento e a construção dos instrumentos de planejamento do SUS', houve unanimidade das falas sobre o subfinanciamento do SUS, sendo essa condição crônica e presente desde a sua criação, na década de $1990 .{ }^{21,22}$ Os entrevistados destacaram a grande dificuldade de se construir os instrumentos de planejamento baseado nas necessidades da população, quando o recurso financeiro não acompanha o crescimento ou a flutuação do número de habitantes nos municípios. Além disso, sua execução também fica comprometida pela falta de recursos financeiros, humanos e políticos.
Agora um problema que a gente sente foi com a cana, o plantio de cana. Nós tivemos muitos migrantes, (...) essa população ela incha, quer dizer, dá um diferencial, no que nós tínhamos programado inicialmente. (E14)

Dizer que a programação anual está sendo levada à risca eu estaria mentindo, nenhum município consegue isso, mesmo porque a gente tem dificuldade orçamentária, de recursos humanos, dificuldade peculiares à própria ação política. (E18)

Reforçando a fala acima, foi relato que o financiamento inadequado compromete a contratação de profissionais por meio de vínculos empregatícios estáveis, pois, além do aporte financeiro insuficiente, a Lei de Responsabilidade Fiscal (LRF) limita os gastos com recursos humanos. Essa lei tinha como objetivo básico regular a responsabilidade da gestão fiscal, no sentido de zelo com as finanças públicas. ${ }^{23}$ Por outro lado, considerando os princípios do SUS e a abrangência desse sistema, a LRF tornou-se um nó crítico ao processo de gestão, pois limitou legalmente a contratação de recursos humanos admitidos por concurso públicos, sob condição de pena criminal para os gestores que não a cumprirem ${ }^{24}$. Sabidamente, a saúde só se faz com pessoas, e a limitação de verbas para contratação de trabalhadores impacta diretamente a qualidade da assistência, o acesso e a precarização do vínculo empregatício dos profissionais de saúde. ${ }^{24}$

Foi tirada uma verba da saúde, o que fica difícil na contratação de funcionários e médicos. É uma firma [empresa] que faz a contratação de médicos - são apenas cinco médicos, mas está difícil. (E15)

Para tentar garantir alguma verba a mais para as ações e serviços de saúde municipais, alguns gestores relataram terem aderido a políticas indutoras, que vinculam a execução de projetos do governo federal ao maior aporte de verbas para os municípios. Todavia, esses projetos não abarcam a heterogeneidade dos municípios do Brasil e muitas vezes não retratam a real ne- 
cessidade da população local, principalmente, para os municípios de pequeno porte e com pouca arrecadação de tributos, onde a escolha de políticas indutoras se caracteriza, muitas vezes, como opção pela falta de recursos próprios oriundos dos impostos e das contribuições fiscais. Vilasboas e Paim ${ }^{20}$ apontam para o desafio posto pelo forte papel indutor exercido pelo governo federal, mediante mecanismos de transferência de recursos financeiros para os municípios em função de sua adesão a determinadas políticas, negociadas nas instâncias intergestores. Essa indução que na década de 1990 teve relativo sucesso na municipalização da gestão do SUS, com as Normas Operacionais Básicas (NOB), hoje tem sido responsável por constrangimentos na organização do sistema devido a concentração política e financeira na esfera federal. ${ }^{15}$

O município tem dificuldade de arrecadação, aqui não tem indústrias, então praticamente ele vive de FTM, dos repasses dos blocos de financiamento federal e os termos estaduais, então a gente sobrevive dessa forma, então muita coisa você até coloca no plano, mas nem sempre ele pode ser realizado. (E12)

Ó, isso já foi prioridade e não é mais, a política mudou, então por exemplo "ai, no meu outro orçamento eu pensei em construir uma clínica para dependência química", mas ó mas o que ta falando... hoje, por exemplo, não deve fazer clínica, deve fazer CAPS, deve fazer isso. (E13)

Para além dessas dificuldades, pode-se questionar o uso dos instrumentos de planejamento nos moldes preconizado pelo MS, se baseadas nas necessidades da população ou em políticas que possam trazer maior financiamento para os municípios. Exemplo disso, aparece na fala de alguns membros da equipe de planejamento, os quais entendem as diretrizes da União como algo que deve ser seguido por todos os municípios, sem priorizar as características e as necessidades de sua população para se adequar às normas nacionais.
O sistema de saúde ele como um todo ele é uma cartilha, (...) então "o SUS preconiza isso, fazemos!", mas a precisão não é tão boa. (E5)

Para Ibañez ${ }^{15}$ a indução do financiamento federal, nos dias atuais, é importante, mas tem se mostrado ineficiente e resulta em sobrecarga dos entes subnacionais, principalmente os municípios. As políticas indutoras geram comprometimento do orçamento dos entes executores para o custeio dos serviços, o que reforça o modelo fragmentado e competitivo. ${ }^{15}$

Outro aspecto que resulta do financiamento inadequado do setor saúde são as ações judiciais como uma forma de exigir que o direito previsto na Constituição Federal/88 seja cumprido pelo Estado. As ações decorrem tanto do aumento da democracia e da inclusão social como da debilidade do Poder Legislativo, ao manter certas indefinições nas leis, e do Poder Executivo, ao não definir prioridades de gastos de acordo com a real necessidade da população. ${ }^{25}$ Para os técnicos e gestores desta pesquisa, a "judicialização" da saúde dificulta o cumprimento do planejamento devido ao curto prazo para serem atendidas e ao uso do recurso financeiro realocado para responder a essas ações pontuais.

Os recursos são, como eu te falei, são finitos, a gente fez aquela programação mas às vezes acontece uma emergência, por exemplo, aqui no município está chegando muito ação judicial (...) hoje abriu tanto que a gente tem em torno de, por dia tem chego em torno de sete processos, então tudo isso interfere no plano municipal, então tem uma certa dificuldade eu vejo, que não dá para a gente atingir as metas que é colocada dentro do plano. (E19)

Além dos problemas com o financiamento, a morosidade da burocracia brasileira no setor público tem impacto direto na execução do planejamento, pois muitos municípios não conseguem receber parte do financiamento do Estado e da União a tempo de executar as ações previstas naquele plano. Para Paim e Teixeira ${ }^{24}$ a burocracia é uma das características do Estado brasi- 
leiro, assim como o autoritarismo, o clientelismo político e a colonização por interesses privados. Esses atributos do Estado, que afetam diretamente a reforma democrática proposta pela reforma sanitária e iniciada pelo SUS, são defendidos pelo pretexto de "governabilidade" do país ${ }^{24}$.

Existem algumas coisas do planejamento que infelizmente você depende de verba estadual, verba federal e existe uma burocracia muito grande no poder público para você conseguir essas verbas, existe uma demora muito grande, é muito documento, é muita coisa, você manda uma coisa não serve, manda outra tá errada, (...) isso acaba dificultando um pouco a gente levar adiante aquilo que estava planejado. (E18)

Além do subfinanciamento crônico, colaboram para a desvalorização do SUS a valorização do setor privado, relatada nas entrevistas, quando se faz comparações injustas entre o setor privado e o público, uma vez que a saúde pública tem que oferecer, além da assistência, toda a parte de vigilância sanitária e epidemiológica e assistência odontológica, que não são obrigatórias nos planos privados de saúde. O setor público também acaba sendo prejudicado devido ao ressarcimento às pessoas físicas e jurídicas pela contratação de planos privados de saúde, em forma de redução de imposto de renda a pagar, e a renúncia fiscal de entidades sem fins lucrativos e da indústria químico-farmacêutica. ${ }^{22}$

Se você colocar que o SUS gasta hoje por mês, por habitante, por pessoa em torno de $\mathrm{R} \$ 40,00$. Qualquer plano de saúde hoje, (...), de 0 a 90 anos de idade é em torno de $\mathrm{R} \$ 140,00 \ldots$ três vezes mais em investimento. (...) É muito fácil falar gestão, gestão, gestão, mas a gente faz milagre. Então, não sei se é tanto gestão com tão pouco dinheiro para tudo o que a gente faz. (E4)

\section{CONCLUSÕES}

Os achados desse estudo apontaram que a principal potencialidade do CGR, atual $C I R$, em relação ao processo de planejamento foi a possi- bilidade empírica de permitir constantes trocas de experiência e de informações entre seus membros. As principais limitações desse espaço foram relacionadas à dificuldade de se compreender a dinâmica das reuniões pela inexperiência dos gestores e técnicos que assumiram o cargo pela primeira vez, além da falta de disponibilidade para participar das reuniões do CGR, relacionadas principalmente aos municípios de pequeno porte, nos quais o aspecto técnico-administrativo acaba sendo, muitas vezes, centrado em um único indivíduo. Esses achados refletem a necessidade de melhorias na condução técnica do ente estadual, principalmente relacionada à definição do papel do CGR, bem como repensar estratégias para incrementar a participação de municípios de pequeno porte nesses espaços, tendo em vista que eles são a maioria nas RS. Outra questão apontada foi a falta de coesão do espaço devido ao desnivelamento de conhecimento acerca do planejamento do SUS entre os participantes e as desigualdades financeiras dos municípios, deixando evidente a necessidade de se repensar a coordenação federativa, com ênfase na definição do papel de cada município dentro da RS, na ordenação de demandas e nos repasses orçamentários.

O processo de planejamento também mostrou ser fortemente influenciado pela continuidade das pessoas que compõem a equipe de planejamento, devido à experiência adquirida nessa área, apesar da grande rotatividade nesses cargos a cada nova gestão municipal. Para minimizar esses efeitos, o aporte técnico do estado no CGR e a construção dos instrumentos de planejamento constituem-se meios fundamentais para a continuidade administrativa, independentemente da alternância política nos municípios.

Porém, a construção dos instrumentos de planejamento encontrou limitações tanto na ausência de cultura de planejamento no ambiente da gestão, que conduz a execução de ações segundo a visão de mundo de cada ator social envolvido no processo, como também na dificuldade de construí-los com base na necessidade da população. Esse segundo ponto foi relacionado ao subfinanciamento crônico do SUS, que influencia fortemente a adesão às políticas indutoras nacionais por parte dos municípios, as quais não corresponderiam necessariamente as suas reali- 
dades. Para a melhoria do primeiro aspecto, aponta-se para a necessidade de oferta de capacitação para os novos técnicos e gestores sobre a operacionalização do planejamento do SUS, bem como atualizações para aqueles que se mantém na gestão, a fim de acompanhar a dinamicidade das normativas que regem o funcionamento do sistema. Com relação ao subfinanciamento do SUS, além da dificuldade para incluir as ações de saúde nos instrumentos de planejamento com base nas necessidades dos municípios também foi relatado o seu impacto negativo sobre a execução das ações planejadas, principalmente referente à contratação de profissionais, o cumprimento de ações judiciais e a burocracia para os repasses dos entes supramunicipais.

Vale notar que a pesquisa não teve a pretensão de esgotar o tema investigado. Como limitação do estudo registra-se que a abordagem metodológica utilizada restringiu-se à interpretação das falas dos participantes, não havendo o cotejamento com as informações registradas nos instrumentos de planejamento produzidos pelas equipes das regiões de saúde estudadas.

\section{REFERÊNCIAS BIBLIOGRÁFICAS}

1. Ministério do Estado da Saúde (Brasil). Ministério da Saúde. Portaria no 399/GM, de 22 de fevereiro de 2006. Divulga o pacto pela Saúde 2006 e aprova as diretrizes operacionais do referido pacto. Diário Oficial da União 23 fev 2006.

2. Ministério da Saúde (Brasil). Sistema de Planejamento do SUS (PlanejaSUS): uma construção coletiva - trajetória e orientações de operacionalização. Brasília: Ministério da Saúde; 2009. (Série B. Textos Básicos de Saúde)

3. Ministério da Saúde (Brasil). Colegiado de gestão regional na região de saúde intraestadual: orientações para organização e funcionamento. Brasília: Ministério da Saúde; 2009. (Série Pactos pela Saúde 2006)

4. Brasil. Decreto no 7.508 de 28 de junho de 2011 . Regulamenta a Lei no 8.080/ 1990. Diário Oficial da União 29 jun 2011.

5. Carvalho ALB, Jesus WLA, Senra IMVB. Regionalização no SUS: processo de implementação, desafios e perspectivas na visão crítica de gestores do sistema. Ciênc saúde coletiva., 2017; 22:1155-64.

6. Bretas Junior N, Shimizu HE. Reflexões teóricas sobre governança nas regiões de saúde. Ciênc saúde coletiva. 2017; 22:1085-95.

7. Departamento de Informática do SUS [homepage na internet]. População estimada segundo município - Informações demográficas e socioeconômicas [acesso em 2017 agosto 25]. Disponível em: http:/ /tabnet.datasus.gov.br/cgi/tabcgi.exe?ibge/cnv/ poptsp.def.
8. Bardin L. Análise de conteúdo. Lisboa: Edições 70; 2000

9. Minayo MCS. O desafio do conhecimento: metodologia de pesquisa social (qualitativa) em saúde. 8. ed. São Paulo: Hucitec; 2004.

10. Oliveira GA, Cândido AM, Melo CMR, Souza ECF, Rodrigues SMM. A regionalização do SUS: uma experiência de construção participativa no contexto do Pacto pela Saúde. In: Conselho Nacional de Secretários de Saúde (CONASS). Realidades e perspectivas da gestão estadual do SUS: coletânea de artigos dos Secretários Estaduais de Saúde. Brasília: CONASS; 2010. p. 51-58.

11. Viana ALD, Lima LD. Avaliação nacional das Comissões Intergestores Bipartites ( $\mathrm{ClBs}$ ): as $\mathrm{ClBs}$ e os modelos de indução da regionalização. Relatório teórico-metodológico: 2010. Rio de Janeiro: Fiocruz; 2010.

12. Campos GWS. O anti-Taylor e o método Paideia: a produção de valores de uso, a produção de sujeitos e democracia institucional. Campinas. Tese [Livredocência] - Faculdade de Ciências Médicas da Universidade de Campinas; 2000.

13. Spink PK. Continuidade e descontinuidade administrativa: uma análise de fatores que contribuem para a manutenção de programas, projetos e atividades públicas de êxito em governos locais brasileiros. Relatório de Pesquisa:2001. São Paulo: EAESP/FGV/NNP; 2001.

14. Organização mundial de saúde. Manual para monitorização e avaliação de recursos humanos de saúde: com aplicação dedicada a países de rendimento baixo e médio. Genebra-Suiça: OMS; 2009.

15. Ibañez N. Cebes debate caminhos para consolidar - direito universal à saúde no Brasil. CEBES [homepage na internet]. 2014. [acesso em 13 ag 2015]. Disponível em: <http://cebes.org.br/2014/ 04 / cebes-promove-debate-sobre-caminhos-para-0direito-universal-a-saude/ $>$.

16. Oliveira JAP. Desafios de planejamento em políticas públicas: diferentes visões e práticas. RAP. 2006; 40: 273-88.

17. Matus C. Política, planejamento e governo. Brasília: I pea; 1996.

18. Vieira FS. Avanços e desafios do planejamento no Sistema Único de Saúde. Ciênc saúde coletiva. 2009; 14( Suppl 1): 1565-77.

19. Testa M. Pensamento estratégico e a lógica da programação. São Paulo: Hucitec; 1994.

20. Vilasbôas ALQ, Paim JS. Práticas de planejamento e implementação de políticas no âmbito municipal. Cad. Saúde Pública. 2008; 24: 1239-50.

21. Alvarezi AM. A ABEn na defesa intransigente do SUS. Rev. bras. enferm. 2015; 68: 185-6.

22. Mendes A, Weiller JAB. Renúncia fiscal (gasto tributário) em saúde: repercussões sobre o financiamento do SUS. Saúde Debate; 2015; 39: 491-505.

23. Saddy A. Lei de responsabilidade fiscal e democratização da gestão pública. Revista Jus Vigilantibus. 2002; 9: 2002.

24. Paim JS, Teixeira CF. Configuração institucional e gestão do Sistema Único de Saúde: problemas e desafios. Ciênc saúde coletiva. 2007; 12 (suppl): 1819-29.

25. Fleury S. Judicialização pode salvar o SUS. Saúde em Debate. 2012; 36: 159-62. 